$[4]$

\title{
Estimation of the diurnal variation of potential evaporation from a wet bare soil surface
}

\author{
Marc B. Parlange and Gabriel G. Katul \\ Hydrologic Science, Department of Land, Air and Water Resources, Veihmeyer Hall, University of \\ California, Davis, CA 95616, USA
}

(Received 14 May 1991; revised and accepted 14 July 1991)

\begin{abstract}
Parlange, M.B. and Katul, G.G., 1992. Estimation of the diurnal variation of potential evaporation from a wet bare soil surface. J. Hydrol., 132: 71-89.

Potential evaporation from a wet bare soil field was measured with a large sensitive weighing lysimeter on a $20 \mathrm{~min}$ time step for 5 days at Davis, California. The diurnal evaporation rate modeled with the Penman-Brutsaert model for potential evaporation with atmospheric stability corrections resulted in the best description of the measured fluxes. The Priestley-Taylor model was accurate for short intervals except when conditions of minimal advection were exceeded during the day. It was noted that the Priestley-Taylor formulation with $\alpha=1.26$ performs best under unstable atmospheric conditions. During stable conditions, the value of $\alpha=1.26$ underpredicts the measured potential evaporation. The advection-aridity model for actual evaporation based on the Bouchet complementary relationship was studied. Strong advection explains the tendency found in other experimental studies to underpredict daily potential evaporation. A methodology to account for the excess advection is discussed in the complementary model, and the flux predictions were equivalent to the Penman-Brutsaert formulation for wet surfaces.
\end{abstract}

\section{INTRODUCTION}

A number of recent hydrologic studies have compared and evaluated different models for prediction of daily evaporation for applications in hydrologic modeling (e.g. Ali and Mawdsley, 1987; Doyle, 1990; Granger and Gray, 1990; Le Meur and Lu, 1990; Nullet and Giambelluca, 1990). These investigations are important in establishing the reliability of daily evaporation formulations. There is, however, a need for surface flux parameterization shorter time periods and when the diurnal variation of evaporation is needed. Shuttleworth (1988) noted that the time scales for hydrologic-climatic simulation are short by conventional hydrologic standards (i.e. 1 day). The atmosphere responds rapidly to the input of energy and water at the land surface and the characteristic atmospheric turbulent time scales range from 10 to 45 min (Wyngaard, 1990; Parlange and Brutsaert, 1990). Sensitivity studies 
with general circulation models (GCMs) have demonstrated the strong interdependence between land surface processes and the atmosphere (see Rowntree and Bolton, 1983; Mintz, 1984). As a result, climate modelers now use short-duration evaporation models which depend on more detailed descriptions of the surface processes (e.g. Dickinson et al., 1986; Sellers and Dorman, 1987). The evaporation component in the GCMs has been demonstrated to play a controlling role in the likelihood of droughts (Rind et al., 1990), the increased vigor of the hydrologic cycle and the diurnal range of surface temperatures over deserts (Warrilow and Buckeley, 1989).

Evaporation models for short durations are necessary also for more precise hydrologic investigations of surface hydrology and groundwater recharge (Abramopoulos et al., 1988). Evaporation is second in magnitude to precipitation in the hydrologic cycle, and in some regions more than $70 \%$ of the precipitation is evaporated (Brutsaert, 1982, 1986; Eagleson, 1986; Kustas, 1990). Water transport in soils is also strongly dependent on the diurnal variation of evaporation.

Quantifying evaporation from bare soil is critical for water resources development in arid regions and for bare or fallow agricultural lands (Soares et al., 1988; Wallace et al., 1990; Le Meur and Lu, 1990). Le Meur and Lu (1990) commented that a typical characteristic of arid regions is that potential evaporation is extremely high and available water is limited, emphasizing the need for accurate and robust potential evaporation models. The purpose of this study is to identify the capabilities of three models to describe the diurnal variation of potential evaporation over bare soils. The models studied are the Penman-Brutsaert potential evaporation model (Katul and Parlange, 1991), the Priestley and Taylor (1972) potential evaporation model, and the advection-aridity actual evaporation model (Brutsaert and Stricker, 1979) based on the Bouchet (1963) complementary relationship. These models require atmospheric measurements at only one level and no calibration of surface properties. They are compared with potential evaporation measurements on a 20 min time step, by means of a large weighing lysimeter (Pruitt and Angus, 1960) with wet bare soil, for 5 days in 1990 at Davis, California.

MODEL BACKGROUND

The Penman-Brutsaert model $\left(\mathrm{E}_{p}\right)$

The Penman (1948) potential evaporation equation is

$E_{\mathrm{p}}=W\left(R_{\mathrm{n}}-G\right)+(1-W) E_{\mathrm{A}}$

where $E_{\mathrm{p}}$ is the potential evaporation, $W=\Delta /(\Delta+\gamma)$ a dimensionless 
weighing function, $\Delta$ the slope of the saturation vapor pressure-temperature curve, $\gamma$ the psychrometric constant and $E_{\mathrm{A}}$ is the drying power of the air. The first term in the Penman equation is referred to as the equilibrium evaporation (Slatyer and McIlroy, 1961; Brutsaert, 1982). $E_{\mathrm{A}}$ was presented by Penman as a bulk transfer function for daily or longer intervals expressed as a linear function of the mean horizontal wind speed. For diurnal evaporation estimation, the effect of atmospheric stability is important in the formulation of $E_{\mathrm{A}}$ (Stricker and Brutsaert, 1978; Brutsaert, 1982; Mahrt and Ek, 1984). On the basis of Monin and Obukhov (1954) similarity theory, Brutsaert (1982) suggested that

$$
E_{\mathrm{A}}=k u_{*} \rho\left(q^{*}-q_{\mathrm{a}}\right)\left[\ln \left(\frac{z-d_{0}}{z_{0 \mathrm{v}}}\right)-\psi_{\mathrm{v}}\left(\frac{z-d_{0}}{L}\right)\right]^{-1}
$$

where $k=0.4$ is Von Kármán's constant, $u_{*}=\left(\tau_{0} / \rho\right)^{1 / 2}$ is the friction velocity, $\tau_{0}$ is the surface shear stress, $\rho$ is the density of the air, $d_{0}$ is the displacement height, $z$ is the height of measurement above the surface, $z_{0 \mathrm{v}}$ is the vapor roughness height, and $q_{\mathrm{a}}$ and $q^{*}$ are the specific humidity of the air and the saturation specific humidity at air temperature, respectively. The similarity stability correction function of Monin and Obukhov (1954), $\psi_{\mathrm{v}}$, depends on $y=\left(z-d_{0}\right) / L$ where $L$ is the Obukhov length, defined by

$$
L=\frac{-u_{*}^{3}}{k g\left[H_{\mathrm{v}} /\left(\rho c_{\mathrm{p}} T_{\mathrm{a}}\right)\right]}
$$

and $H_{\mathrm{v}}=\left(H+0.61 T_{\mathrm{a}} C_{\mathrm{p}} E\right)$ is the specific flux of virtual sensible heat, $c_{\mathrm{p}}$ the specific heat at constant pressure, $T_{\mathrm{a}}$ the air temperature, $E$ the actual evaporation rate, and $H$ the specific flux of sensible heat.

The Businger-Dyer stability functions (Dyer, 1974; Businger, 1988) can be described by

$$
\begin{aligned}
& \psi_{v}=2 \ln \left(\frac{1+x^{2}}{2}\right) ; \quad(y<0) \\
& \psi_{v}=5\left[\left(z_{0} / L\right)-y\right] ; \quad(0<y \leqslant 1) \\
& \psi_{v}=-5 \ln \left(\frac{z-d_{0}}{z_{0}}\right) ; \quad(1<y)
\end{aligned}
$$

where $x=(1-16 y)^{1 / 4}$. Equation (4) applies to unstable conditions and eqns. (5) and (6) to stable conditions. The friction velocity is obtained from the Monin-Obukhov model for the mean horizontal wind speed,

$$
V=\frac{u_{*}}{k}\left[\ln \left(\frac{z-d_{0}}{z_{0}}\right)-\psi_{\mathrm{m}}\left(\frac{z-d_{0}}{L}\right)\right]
$$


where $V$ is the mean horizontal wind speed, $z_{0}$ is the surface roughness, and $\psi_{\mathrm{m}}$ is the momentum stability correction function. For stable conditions the momentum correction functions are assumed to be equal to the vapor correction functions, and for unstable conditions

$\psi_{\mathrm{m}}=\ln \left[\frac{(1+x)^{2}\left(1+x^{2}\right)}{\left(1+x_{0}\right)^{2}\left(1+x_{0}^{2}\right)}\right]-2 \arctan x+2 \arctan x_{0}$

where $x_{0}=\left[1-16 z_{0} / L\right]^{1 / 4}$. For a bluff-rough surface (e.g. bare soil) the scalar roughness $\left(z_{0 v}\right)$ may be estimated by

$z_{0 v}=7.4 z_{0} \exp \left[-2.25\left(z_{0+}^{1 / 4}\right)\right]$

where $z_{0+}=\left(u_{*} z_{0}\right) / v$ is the roughness Reynolds number, and $v$ is the kinematic viscosity (Brutsaert, 1975; Katul and Parlange, 1991).

The evaporation is determined with an iteration procedure in the context of the one-dimensional surface energy budget,

$R_{\mathrm{n}}-G=E_{\mathrm{p}}+H$

where $R_{\mathrm{n}}$ is the net radiation and $G$ is the soil heat flux. The system is initiated by assuming neutral stability conditions $\left(\psi_{\mathrm{v}}=\psi_{\mathrm{m}}=0\right)$ to determine $u_{*}, E_{\mathrm{A}}$, and $E_{\mathrm{p}}$. The initial value of $E_{\mathrm{p}}$ is used to obtain $H$ by means of the energy balance and these initial values of $E_{\mathrm{p}}, u_{*}$ and $H$ provide a first estimate of $L$. The stability correction functions are then included through successive iterations until convergence of $E_{\mathrm{p}}$ is achieved.

Priestley-Taylor Model $\left(\mathrm{E}_{P T}\right)$

Priestley and Taylor (1972) obtained a simple model of the total input of water vapor from a large wet area. They found that under conditions of minimal advection $E_{\mathrm{p}}$ can be described by a constant proportion of the equilibrium evaporation,

$E_{\mathrm{PT}}=\alpha \frac{\Delta}{\Delta+\gamma}\left(R_{\mathrm{n}}-G\right)$

where $E_{\mathrm{PT}}$ is the Priestley-Taylor potential evaporation flux and $\alpha$ is the constant of proportionality. In the context of their work, Priestley and Taylor (1972) concluded that the eddy conductivity of heat $\left(K_{\mathrm{h}}\right)$ and the eddy diffusivity of vapor $\left(K_{\mathrm{v}}\right)$ tend to the eddy viscosity $(K)$ in the atmospheric surface layer. Therefore, assuming similarity with $K_{\mathrm{h}}=K_{\mathrm{v}}=K$, both the specific humidity $q$ and temperature $T$ satisfy the same one-dimensional diffusion equation

$\frac{\partial q, T}{\partial t}=\frac{\partial}{\partial z}\left(K \frac{\partial q, T}{\partial z}\right)$ 
For saturated surfaces, Priestley and Taylor proposed a variable which could satisfy (12), of the form

$$
A=q-q_{\mathrm{s}}(T m)-\left(\frac{\partial q_{\mathrm{s}}}{\partial T}\right)_{T=T m}(T-T m)
$$

where $T m$ is some constant temperature between $T_{\mathrm{s}}$ and $T$, and $q_{\mathrm{s}}$ is the specific humidity at the saturated surface. For $A=0$, the solution yields the equilibrium evaporation $E_{\text {eq }}$ with

$\frac{E_{\mathrm{eq}}}{H_{\mathrm{eq}}+E_{\mathrm{eq}}}=\frac{\Delta}{\Delta+\gamma}$

where $H_{\mathrm{eq}}$ is the sensible heat flux at equilibrium conditions. Equation (14) is not the most general solution to eqn. (12) but only a particular solution resulting from the case $A=0$. Priestley and Taylor studied how much this solution explained the variation of the actual surface fluxes and proposed a modification of the form

$\frac{E_{\mathrm{PT}}}{H_{\mathrm{PT}}+E_{\mathrm{PT}}}=\alpha \frac{\Delta}{\Delta+\gamma}$

where $H_{\mathrm{PT}}$ is the sensible heat flux obtained from the energy budget with a Priestley-Taylor defined evaporative flux. As the proposed solution in eqn. (15) must satisfy the boundary condition $K \partial A / \partial z=0, \alpha$ must be a constant independent of $z / L$. Priestley and Taylor (1972) established that $\alpha$ varies from unity to $(1 / W)$ and that, experimentally, $\alpha=1.26$ for wet land surfaces and free water bodies. That $\alpha$ is about 1.26 shows that the advection-free conditions leading to an equilibrium state (Slatyer and McIlroy, 1961) are extemely unlikely to occur, and large-scale advection from extensive saturated surfaces accounts for roughly $20 \%$ of the evaporation rate (Brutsaert, 1982). This deviation from equilibrium conditions occurs because the turbulent atmosphere is continually responding to large-scale weather patterns that involve condensation and unsteady flow, which maintain a specific humidity deficit even above lakes and oceans (Brutsaert, 1982). Many studies have found that $\alpha$ is approximately equal to 1.26 for a variety of wet surfaces (e.g. Davies and Allen, 1973; Jury and Tanner, 1975; Stewart and Rouse, 1976, 1977; Doorenbos and Pruitt, 1977). The formulation has proven to be useful for humid sites with minimal advection (De Bruin and Holtslag, 1982; Stagnitti et al., 1989). Finally, the Priestley-Taylor method is simple to use, requiring little computational effort, and can yield accurate results if the assumptions of the model are met. 
Advection-aridity model $\left(E_{a a}\right)$

The advection-aridity approach suggested by Brutsaert and Stricker (1979) for evaporation estimates for daily or longer periods relies on a complementary relationship between actual and potential evaporation, as proposed by Bouchet (1963) and developed by others including Morton $(1969,1975,1983)$, Seguin (1975), and Fortin and Seguin (1975). This work was motivated by the need for a model to estimate actual rather than potential evaporation using only regularly measured quantities. The Bouchet complementary relation can be stated as

$E_{\mathrm{p}}+E=2 E_{\mathrm{w}}$

where $E_{\mathrm{p}}$ is the potential evaporation, $E$ is the actual evaporation, and $E_{\mathrm{w}}$ is the evaporation from a wet environment. The potential evaporation is defined by

$E_{\mathrm{p}}=E_{\mathrm{w}}+q_{1}$

where $q_{1}$ is the energy that becomes available when $E$ decreases below $E_{\mathrm{w}}$, in the absence of excess advection (oasis effect). Brutsaert and Stricker suggested that the Priestley-Taylor model should be used to compute $E_{\mathrm{w}}\left(\right.$ i.e. $E_{\mathrm{w}}=E_{\mathrm{PT}}$ ) and the Penman equation to compute $E_{\mathrm{p}}$ (Nash, 1989). The advection-aridity model has proven useful on a daily or monthly basis when compared with field measurements (e.g. Brutsaert and Stricker, 1979; Ali and Mawdsley, 1987; Le Meur and Lu, 1990). When the surface is wet, Ali and Mawdsley (1987) noted that the advection-aridity equation can underestimate the evaporation rate.

\section{EXPERIMENTS}

The sensitive lysimeter research facility is located at the Campbell research site at the University of California, Davis. The soil is a Yolo Clay Loam which was raked to break up surface crust and seal formation. The surface may be classified as bluff-rough with a surface roughness of $2 \mathrm{~cm}$. Applied water was supplied by a sprinkler irrigation system which wets a surface area of $150 \mathrm{~m} \times$ $130 \mathrm{~m}$ at $80-88 \%$ uniformity depending on the mean horizontal wind speed during irrigation (see Cuenca, 1989). The field was irrigated with about $20 \mathrm{~mm}$ of water in the evening before each of the 5 days of the study. The irrigated area is located within a larger bare soil field some $500 \mathrm{~m} \times 500 \mathrm{~m}$. The irrigations supplied were sufficient to wet the upper soil layer and to maintain potential conditions for at least $30 \mathrm{~h}$ in each case.

The evaporative fluxes were measured every $20 \mathrm{~min}$ from a circular sensitive 
weighing lysimeter $\left(E_{\mathrm{wl}}\right), 6 \mathrm{~m}$ in diameter and $1 \mathrm{~m}$ in depth. As lysimeter evaporation measurements can be partially influenced by short bursts and changes in wind speed, a 1:2:1 smoothing filter was applied to the raw flux measurements (see Pruitt and Lourence, 1985). The lysimeter is reliable for measuring evaporation to $0.03 \mathrm{~mm}$ of equivalent water depth (Pruitt and Angus, 1960). The advantage of using a weighing lysimeter is that the water vapor fluxes are obtained independently of the surface energy budget.

The meteorological observations over the $20 \mathrm{~min}$ intervals were temperature $\left(T_{\mathrm{a}}\right)$ and relative humidity $(\mathrm{RH})$ at $0.80 \mathrm{~m}$, mean horizontal wind speed at $2 \mathrm{~m}$, net radiation (Q6 Fritchen net radiometer), and soil heat flux obtained using two plates of constant thermal conductivity. The meteorological station is located north-central in the field to maximize fetch, as the winds are predominantly from the south and southeast. The days studied were Julian days $257,271,279,286$ and 297 (1990).

\section{RESULTS AND DISCUSSION}

The three models were evaluated on 20 min time intervals throughout each of the 5 days. The fluxes estimated with the models $\left(E_{\mathrm{m}}\right)$ and measured with the lysimeter $\left(E_{\mathrm{wl}}\right)$ are plotted for each day in Figs. 1-5. The drying power of the air $\left(E_{\mathrm{A}}\right)$ is included as a reference to indicate the importance of advection for each of the 5 days. Linear regression analyses of the model estimates on the lysimeter measurements, for each day, are summarized in Table 1. The Penman-Brutsaert model $\left(E_{\mathrm{p}}\right)$ performed consistently well, under a variety of

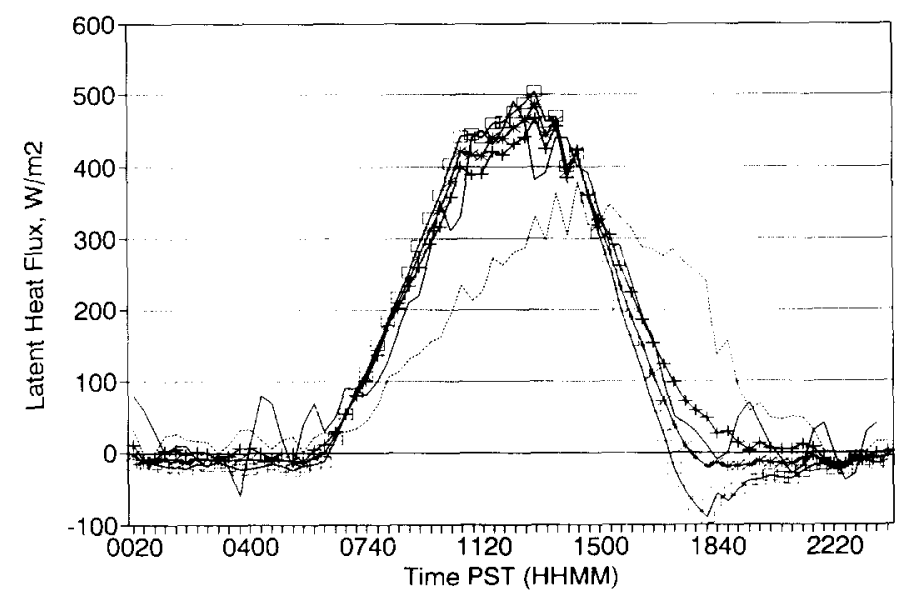

Fig. 1. Comparison between the Penman-Brutsaert model $E_{\mathrm{p}}(+)$, the Priestley-Taylor model $E_{\mathrm{PT}}$ with $\alpha=1.26(*)$, and the advection-aridity model $E_{\mathrm{aa}}(\square)$. The weighing lysimeter $E_{\mathrm{w} t}$ (solid line), and the drying power of the air $E_{\mathrm{A}}$ (broken line) are also shown for Julian day 257, 1990. 


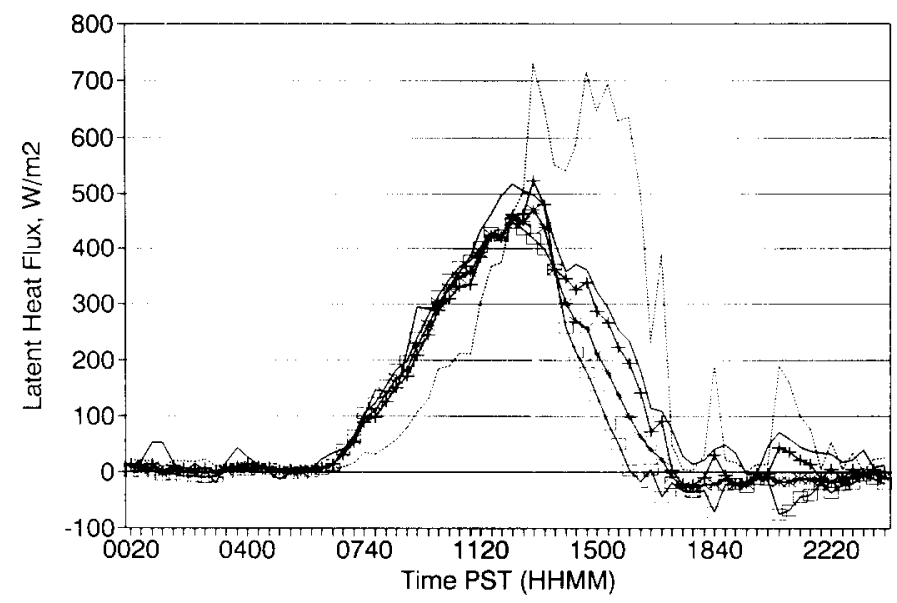

Fig. 2. Same as Fig. 1 for Julian day 271, 1990.

atmospheric conditions. The Priestley-Taylor model $\left(E_{\mathrm{PT}}\right)$ and the advectionaridity $\left(E_{\mathrm{aa}}\right)$ models predicted the diurnal evaporation rate well when radiation was the primary mechanism forcing the evaporation. Once the drying power of the air exceeded the available energy $\left(R_{\mathrm{n}}-G\right)$, both the PriestleyTaylor and the advection-aridity models underpredicted the measured evaporation. The effect of advection played an important role in the evaporation process, even for 1 day, when the wind speed increased. The model and measurement comparisons are presented and discussed for each day. The effect of local advection, which results in a negative sensible heat flux, is discussed in the context of the advection-aridity model.

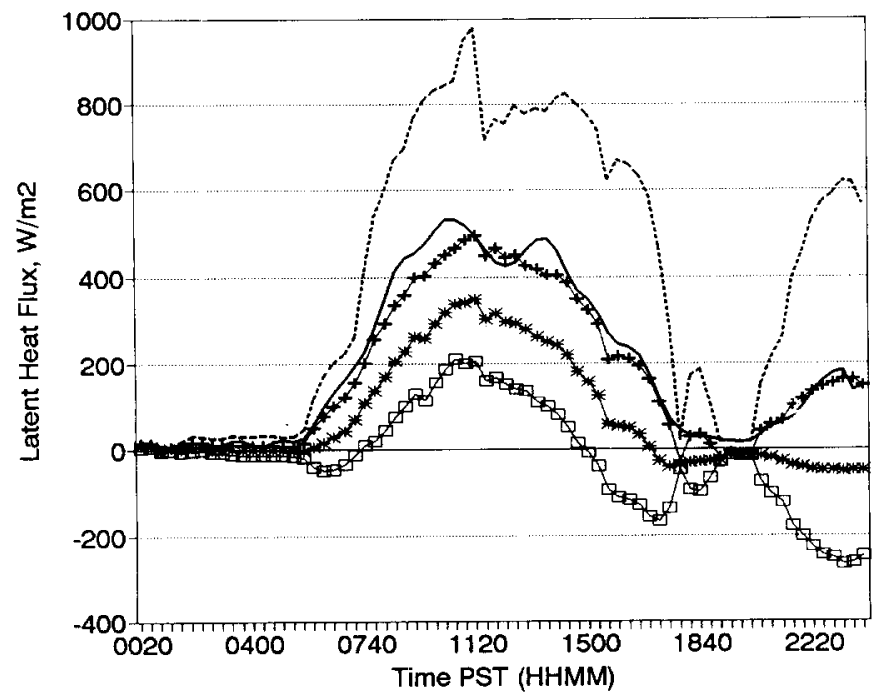

Fig. 3. Same as Fig. 1 for Julian day 279, 1990. 


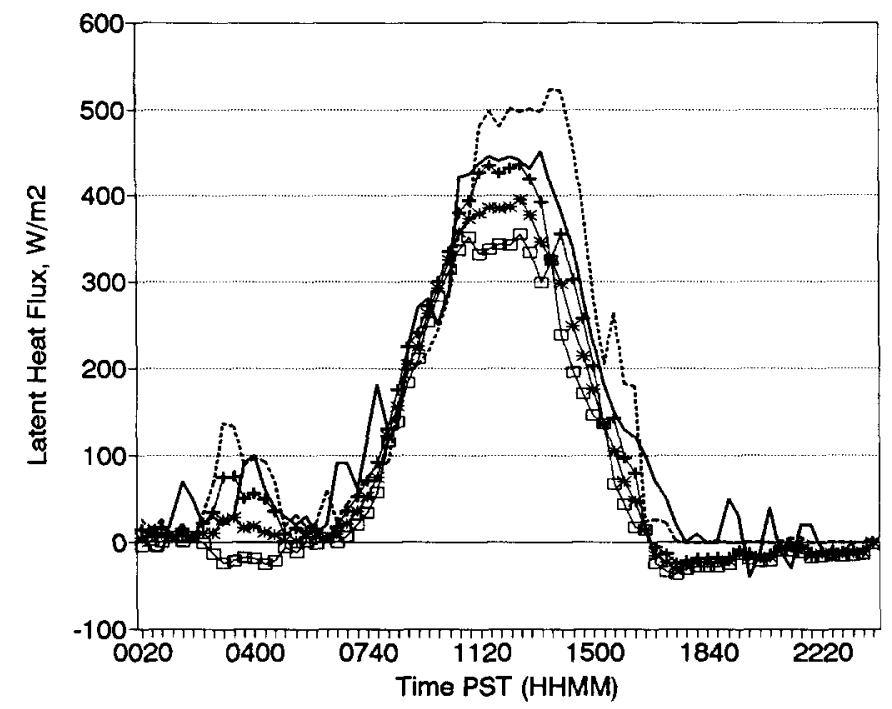

Fig. 4. Same as Fig. 1 for Julian day 286, 1990.

Julian day 257 (Fig. 1)

Evaporation was controlled mainly by radiation and all the models compared well with $E_{\mathrm{wl}}$. When $E_{\mathrm{A}}$ exceeded the available energy, at about 15:00 h, both $E_{\mathrm{PT}}$ and $E_{\mathrm{aa}}$ dropped below the measured fluxes, though later $(16: 00 \mathrm{~h})$ the Penman-Brutsaert estimates exceeded the lysimeter measurements. The $R^{2}$ values (see Table 1) were above 0.9 for each of the models on this day. However, only the slope of the Penman-Brutsaert model was not found to be statistically different from unity, indicating that the drying power of the air

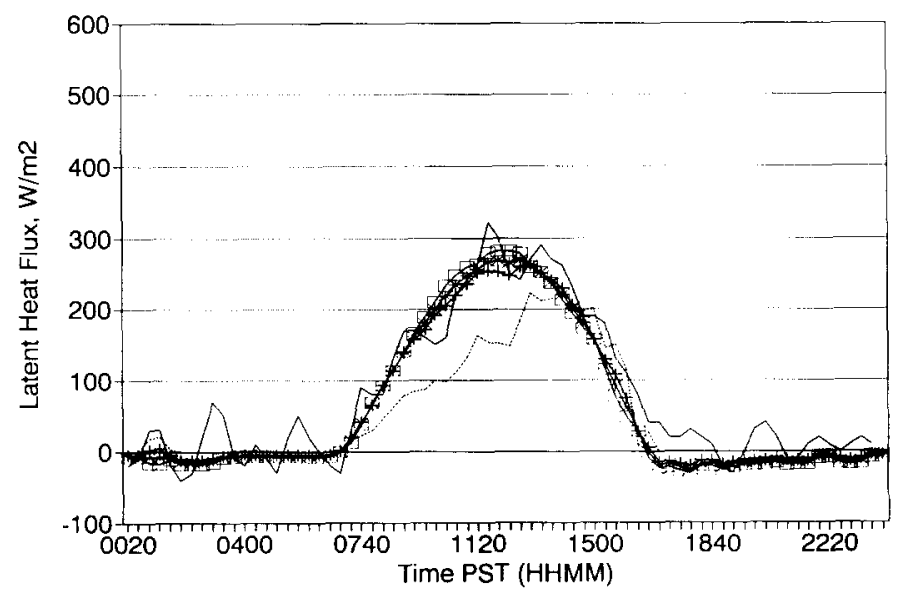

Fig. 5. Same as Fig. 1 for Julian day 297, 1990. 


\section{TABLE 1}

Linear regression results for model $E_{\mathrm{wl}}=A\left(E_{\mathrm{m}}\right)+B$ with the $Z$ statistic for a $95 \%$ confidence level to check the hypothesis that the slope $A$ is not statistically different from unity (T, hypothesis true; F, hypothesis false)

\begin{tabular}{|c|c|c|c|c|c|c|}
\hline $\begin{array}{l}\text { Julian } \\
\text { day }\end{array}$ & Method & $R^{2}$ & $\begin{array}{l}\text { SEE } \\
\left(\mathrm{W} \mathrm{m}^{-2}\right)\end{array}$ & Slope & 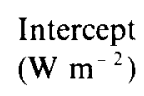 & $\begin{array}{l}Z \\
\text { statistic }\end{array}$ \\
\hline \multirow[t]{4}{*}{257} & $E_{\mathrm{p}}$ & 0.95 & 38.37 & 0.97 & -1.4 & $0.36(\mathrm{~T})$ \\
\hline & $E_{\mathrm{PT}}$ & 0.95 & 37.60 & 0.90 & 25.22 & $3.82(\mathrm{~F})$ \\
\hline & $E_{\text {aа }}$ & 0.93 & 43.27 & 0.83 & 41.66 & $6.35(\mathrm{~F})$ \\
\hline & $E_{\text {adj }}$ & 0.94 & 39.55 & 0.91 & 5.98 & $3.16(\mathrm{~F})$ \\
\hline \multirow[t]{4}{*}{271} & $E_{\mathrm{p}}$ & 0.98 & 22.86 & 0.95 & -17.76 & $1.30(\mathrm{~T})$ \\
\hline & $E_{\mathrm{PT}}$ & 0.95 & 36.18 & 1.04 & 35.28 & $1.30(\mathrm{~T})$ \\
\hline & $E_{\text {aа }}$ & 0.86 & 61.40 & 0.97 & 56.20 & $0.60(\mathrm{~T})$ \\
\hline & $E_{\mathrm{adj}}$ & 0.98 & 24.20 & 0.99 & 16.13 & $0.31(\mathrm{~T})$ \\
\hline \multirow[t]{4}{*}{279} & $E_{\mathrm{p}}$ & 0.98 & 24.95 & 0.93 & -4.88 & $1.94(\mathrm{~T})$ \\
\hline & $E_{\mathrm{PT}}$ & 0.87 & 66.86 & 1.33 & 91.03 & $5.34(\mathrm{~F})$ \\
\hline & $E_{\mathrm{aa}}$ & 0.30 & 155.4 & 0.97 & 222.6 & $0.19(\mathrm{~T})$ \\
\hline & $E_{\text {adj }}$ & 0.98 & 30.69 & 1.19 & -3.28 & $8.04(F)$ \\
\hline \multirow[t]{4}{*}{286} & $E_{\mathrm{p}}$ & 0.97 & 30.9 & 0.96 & -14.05 & $0.76(\mathrm{~T})$ \\
\hline & $E_{\mathrm{PT}}$ & 0.97 & 29.37 & 1.11 & 27.03 & $4.32(\mathrm{~F})$ \\
\hline & $E_{\text {aа }}$ & 0.94 & 38.40 & 1.17 & 41.18 & $4.91(\mathrm{~F})$ \\
\hline & $E_{\text {adj }}$ & 0.96 & 30.26 & 1.11 & 15.52 & $4.36(\mathrm{~F})$ \\
\hline \multirow[t]{4}{*}{297} & $E_{\mathrm{p}}$ & 0.96 & 24.40 & 0.95 & -15.01 & $0.82(\mathrm{~T})$ \\
\hline & $E_{\mathrm{PT}}$ & 0.93 & 28.22 & 0.95 & 20.60 & $1.58(\mathrm{~T})$ \\
\hline & $E_{\text {aa }}$ & 0.91 & 30.42 & 0.90 & 23.91 & $2.68(\mathrm{~F})$ \\
\hline & $E_{\text {adj }}$ & 0.92 & 29.20 & 0.96 & 11.53 & $1.30(\mathrm{~T})$ \\
\hline
\end{tabular}

corrected for stability is important when short time fluxes (less than $1 \mathrm{~h}$ ) are calculated. On a daily time step, the average daily fluxes of all models for day 257 were not statistically different from the average measured lysimeter flux (see Table 2). Therefore on a daily time step, in which radiation predominates over the evaporation process, accounting for atmospheric stability is not necessary and the simple formulation suggested by Priestley and Taylor (1972) with an $\alpha=1.26$ is adequate. In general, when radiation predominates over the evaporation process, the sensible heat flux is positive and the friction velocity is relatively small. This results in a negative Obukhov length, associated with unstable stability conditions, and the value of $\alpha=1.26$ is accurate for flux predictions using the Priestley-Taylor or the advection-aridity formulations. 


\section{TABLE 2}

Daily comparisons between model predictions and lysimeter measurements with the $Z$ statistic for a $95 \%$ confidence level to check the hypothesis that the average daily lysimeter flux is not statistically different from the average daily computed flux ( $T$, hypothesis true; $F$, hypothesis false)

\begin{tabular}{|c|c|c|c|c|}
\hline $\begin{array}{l}\text { Julian } \\
\text { day }\end{array}$ & Method & $\begin{array}{l}\text { Mean daily } \\
\text { flux }\left(\mathrm{W} \mathrm{m}^{-2}\right)\end{array}$ & $\begin{array}{l}\text { Standard } \\
\text { deviation }\end{array}$ & $\begin{array}{l}Z \\
\text { statistic }\end{array}$ \\
\hline \multirow[t]{5}{*}{257} & $E_{\mathrm{w} !}$ & 139.2 & 164.6 & \\
\hline & $E_{\mathrm{p}}$ & 132.9 & 164.7 & $0.33(\mathrm{~T})$ \\
\hline & $E_{\mathrm{PT}}$ & 124.2 & 177.2 & $0.77(\mathrm{~T})$ \\
\hline & $E_{\mathrm{aa}}$ & 115.5 & 191.5 & $1.21(\mathrm{~T})$ \\
\hline & $E_{\text {adj }}$ & 143.9 & 174.5 & $0.23(\mathrm{~T})$ \\
\hline \multirow[t]{5}{*}{271} & $E_{\mathrm{w} 1}$ & 140.9 & 164.5 & \\
\hline & $E_{\mathrm{p}}$ & 116.7 & 157.6 & $1.24(\mathrm{~T})$ \\
\hline & $E_{\mathrm{PT}}$ & 101.9 & 154.9 & $1.99(\mathrm{~F})$ \\
\hline & $E_{\mathrm{aa}}$ & 87.10 & 157.3 & $2.75(\mathrm{~F})$ \\
\hline & $E_{\text {adj }}$ & 125.5 & 163.6 & $0.79(\mathrm{~T})$ \\
\hline \multirow[t]{5}{*}{279} & $E_{\mathrm{w} 1}$ & 194.7 & 184.2 & \\
\hline & $E_{\mathrm{p}}$ & 184.6 & 171.4 & $0.46(\mathrm{~T})$ \\
\hline & $E_{\mathrm{PT}}$ & 77.90 & 129.2 & $5.33(\mathrm{~F})$ \\
\hline & $E_{\mathrm{aa}}$ & -28.8 & 105.7 & $10.2(\mathrm{~F})$ \\
\hline & $E_{\text {adj }}$ & 165.8 & 152.2 & $1.32(\mathrm{~T})$ \\
\hline \multirow[t]{5}{*}{286} & $E_{\mathrm{w} 1}$ & 131.2 & 159.8 & \\
\hline & $E_{\mathrm{p}}$ & 109.5 & 152.0 & $1.14(\mathrm{~T})$ \\
\hline & $E_{\mathrm{PT}}$ & 92.47 & 141.6 & $2.04(\mathrm{~F})$ \\
\hline & $E_{\mathrm{aa}}$ & 75.40 & 132.4 & $2.93(\mathrm{~F})$ \\
\hline & $E_{\text {adj }}$ & 102.4 & 140.8 & $1.51(\mathrm{~T})$ \\
\hline \multirow[t]{5}{*}{297} & $E_{\mathrm{w} 1}$ & 79.1 & 102.3 & \\
\hline & $E_{\mathrm{p}}$ & 61.7 & 99.86 & $1.42(\mathrm{~T})$ \\
\hline & $E_{\mathrm{PT}}$ & 60.7 & 103.4 & $1.50(\mathrm{~T})$ \\
\hline & $E_{\mathrm{aa}}$ & 59.7 & 107.2 & $1.58(\mathrm{~T})$ \\
\hline & $E_{\mathrm{adj}}$ & 69.7 & 102.3 & $0.77(\mathrm{~T})$ \\
\hline
\end{tabular}

Julian day 271 (Fig. 2)

The three models predicted the morning evaporation accurately; when the wind speed increased in the afternoon (more than $4 \mathrm{~m} \mathrm{~s}^{-1}$ ) the atmospheric drying power increased so that the measured evaporation $\left(E_{\mathrm{wl}}\right)$ was greater than either the Priestley-Taylor or the advection-aridity flux estimates (see Table 1). The Penman-Brutsaert model had the lowest standard error of measurement $\left(21.80 \mathrm{~W} \mathrm{~m}^{-2}\right)$, which is less than the estimated measurement 
error of the lysimeter $\left(30 \mathrm{~W} \mathrm{~m}^{-2}\right)$. On a daily time step, the Penman-Brutsaert average latent heat flux was not statistically different from the average flux measured by the lysimeter, unlike the other models, demonstrating that atmospheric stability can play an important role even on a daily time step when the evaporation process is influenced by local advection.

\section{Julian day 279 (Fig. 3)}

The drying power of the air was greater than the net radiation throughout the day, as a result of a combination of strong winds (see Fig. 3) and high vapor pressure deficit. The Penman-Brutsaert model described the measured fluxes well, with a standard error of estimate less than the error in the lysimeter measurement. The predictive capacities of both $E_{\mathrm{aa}}$ and $E_{\mathrm{PT}}$ dropped significantly because of the violation of the minimal advection assumption. The advection-aridity estimates are more affected by the advection than are those of the Priestley-Taylor model. Once $E_{\mathrm{p}}$ is greater than $E_{\mathrm{w}}, E_{\mathrm{ad}}$ symmetrically drops below $E_{\mathrm{w}}$ according to the Bouchet hypothesis, and as the excess advected energy increases the potential evaporation the estimated evaporation rate is reduced. The Bouchet hypothesis is, of course, based on the assumption of minimal advection in the Priestley-Taylor description of $E_{\mathrm{w}}$. On a daily basis, the Priestley-Taylor and the advection-aridity estimates are statistically different from the daily lysimeter measurement. This indicates that vapor transport due to local advection can be significant on a daily time step and radiant energy considerations alone are not sufficient to model accurately the evaporation process.

\section{Julian day 286 (Fig. 4)}

The observations on this day are subject to similar comments to those made for day 271. Afternoon advection was underpredicted by the Priestley-Taylor and the advection-aridity models. Only the Penman-Brutsaert model fully described the variation of the lysimeter readings. Unlike the Priestley-Taylor and the advection-aridity models, the slope of the Penman-Brutsaert regression model was not found to be statistically different from unity. On a daily basis, inferences similar to those for day 271 can be made.

Julian day 297 (Fig. 5)

On this day radiant energy considerations proved to be adequate in describing evaporation throughout the day, reinforcing the discussion presented for day 257 . 


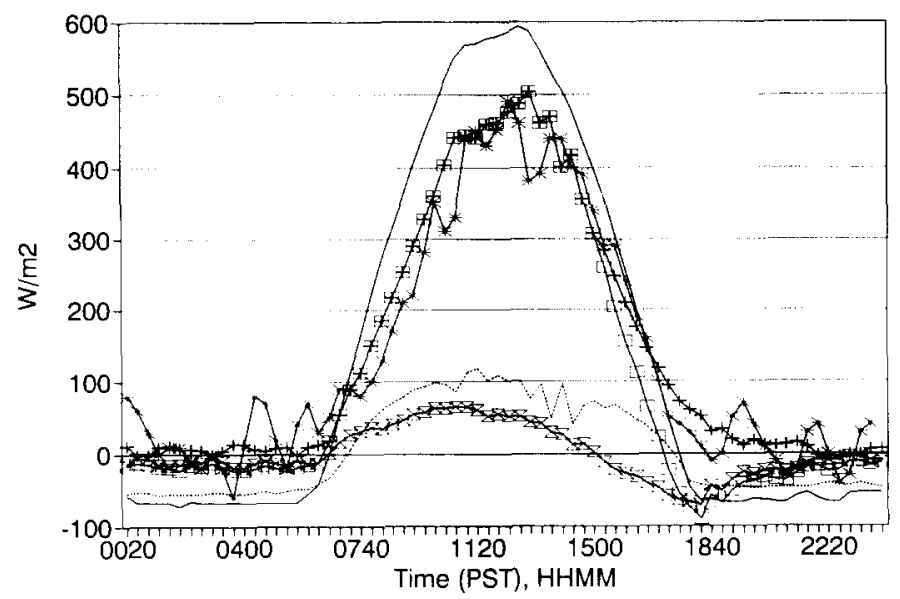

Fig. 6. Comparison between the adjusted advection-aridity $E_{\text {adj }}(+)$, the weighing lysimeter $E_{w 1}(*)$, and the unadjusted advection-aridity $E_{\mathrm{aa}}(\square)$. Net radiation $R_{\mathrm{n}}$ (solid line), soil heat flux $G$ (broken line), and sensible heat flux $H_{\mathrm{p}}(\mathrm{X})$ are also shown for Julian day 257, 1990.

Adjustment to the advection-aridity model: adjusted actual evaporation $\left(\mathrm{E}_{\text {adj }}\right)$

When $E_{\mathrm{p}}$ exceeds the Priestley-Taylor estimate of potential evaporation due to local advection, the Bouchet complementary hypothesis breaks down. An extreme example is demonstrated on day 279 when the actual evaporation rate exceeded the Priestley-Taylor estimates throughout the day. The local advection, which results in $E_{\mathrm{p}}$ exceeding $R_{\mathrm{n}}-G$, causes the sensible heat flux to be negative, which is not accounted for with the advection-aridity model. It is suggested that the sensible heat flux is calculated from the energy budget,

$H_{\mathrm{p}}=R_{\mathrm{n}}-G-E_{\mathrm{p}}$

and that when $H_{\mathrm{p}}$ is negative the absolute $\left|H_{\mathrm{p}}\right|$ value is added to $E_{\mathrm{PT}}$ so that $E_{\mathrm{w}}=E_{\mathrm{PT}}+\left|H_{\mathrm{p}}\right|$ in eqn. (16). The effect of strong local advection is therefore incorporated by increasing the wet surface evaporation rate, and the resulting complementary relation is given by

$E_{\mathrm{p}}+E_{\text {adj }}=2\left(E_{\mathrm{PT}}+\left|H_{\mathrm{p}}\right|\right)$

In Figs. 6-10 the sensible heat flux is plotted in addition to the advectionaridity and the adjusted advection-aridity $\left(E_{\text {adj }}\right)$ evaporation rates. The results of the regression on the adjusted advection-aridity estimates are summarized in Tables 1 and 2. Significant improvements based on the proposed adjustment over the unadjusted advection-aridity $\left(E_{\text {aa }}\right)$ were noted on a daily and $20 \mathrm{~min}$ time step. Moreover, the adjusted advection-aridity model was 


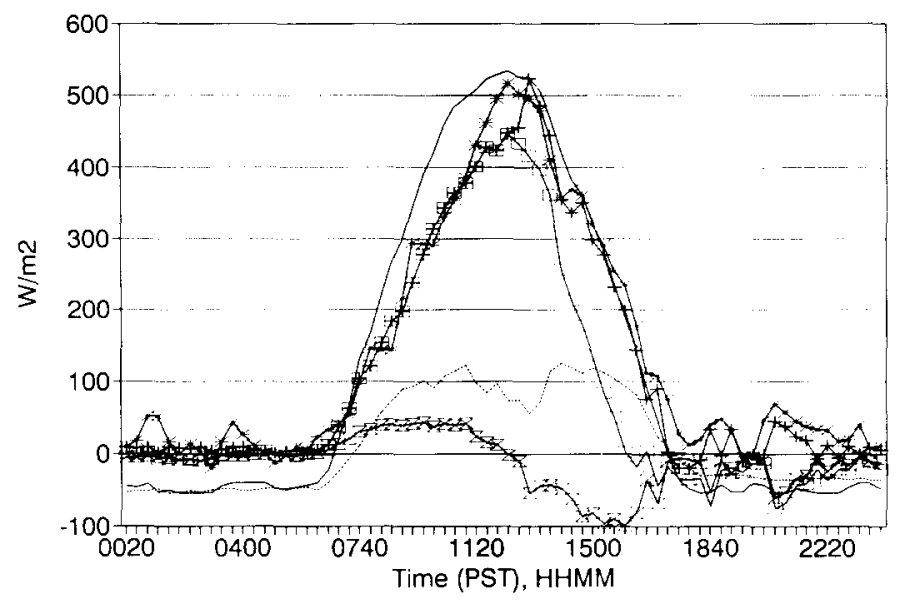

Fig. 7. Same as Fig. 6 for Julian day 271, 1990.

able to capture and model the oasis effect when compared with the $20 \mathrm{~min}$ lysimeter evaporation measurements.

Comment on the effect of atmospheric stability on $\alpha$

Conditions of minimal advection were assumed in the derivation of the Priestley-Taylor (1972) equation (i.e. $H>0$ ). On a short time step, when excess advection occurs, the $E_{\mathrm{A}}$ increases and enhances the vapor removal, so that the sensible heat flux may become negative and stable conditions are established. During the transition from unstable to stable conditions and

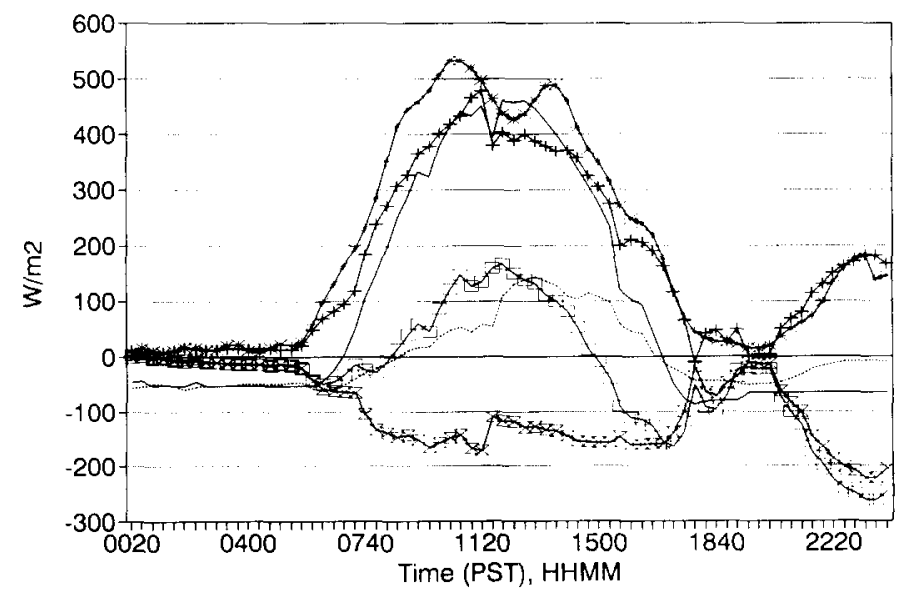

Fig. 8. Same as Fig. 6, for Julian day 279, 1990. 


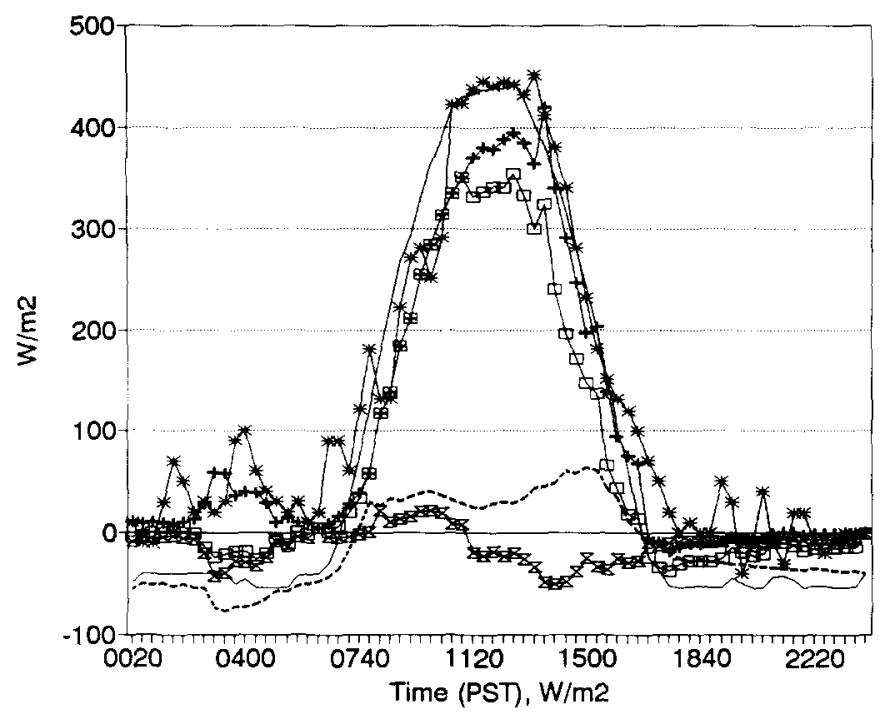

Fig. 9. Same as Fig. 6, for Julian day 286, 1990.

under stable conditions, the Priestley-Taylor $\alpha=1.26$ is obviously not satisfactory, see Fig. 12 for day 271 . When strongly unstable conditions prevail, for example days 257 and 297 (Figs. 11 and 13), the Priestley-Taylor model performs well, as the assumption of $K_{\mathrm{h}}=K_{\mathrm{v}}=K$ is satisfied, and eqn. (12) describes the variation of the temperature and specific humidity profiles with time. Under unstable conditions, the value of $\alpha=1.26$ adequately describes the vapor transport mechanisms during short time intervals.

\section{CONCLUSIONS}

This study of potential evaporation from a bare soil surface demonstrates

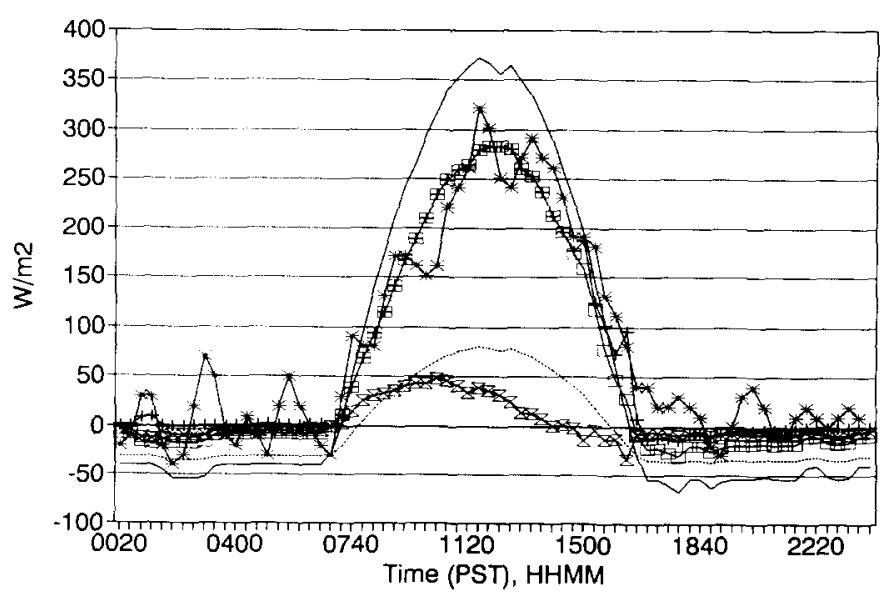

Fig. 10. Same as Fig. 6, for Julian day 297, 1990. 


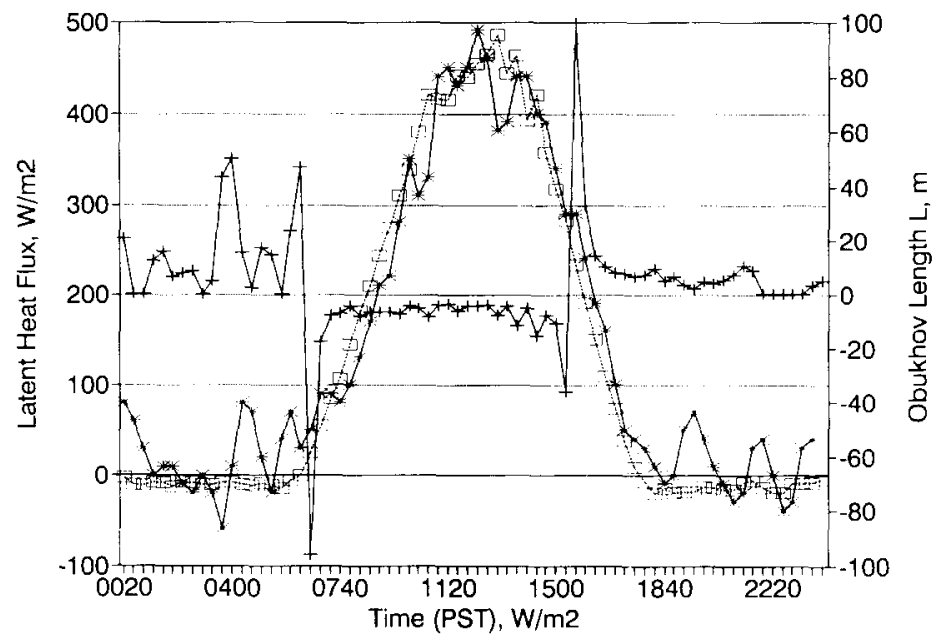

Fig. 11. Effect of atmospheric stability on the Priestley-Taylor $x$. The weighing lysimeter $E_{w 1}(*)$, the Priestley-Taylor model $E_{\mathrm{PT}}(\square)$, and the Obukhov length $L(+)$ are shown for Julian day 257, 1990.

that, with atmospheric stability, the Penman-Brutsaert combination model gives the most accurate measure of the water vapor fluxes for short and daily time steps. The model is robust even when local advection leads to an 'oasis effect'. The Priestley-Taylor model, under conditions of minimal advection is a reliable measure of the daytime and $20 \mathrm{~min}$ evaporation rates. The advection-aridity actual evaporation model, based on the Bouchet complementary relationship, is also accurate for conditions of minimal advection.

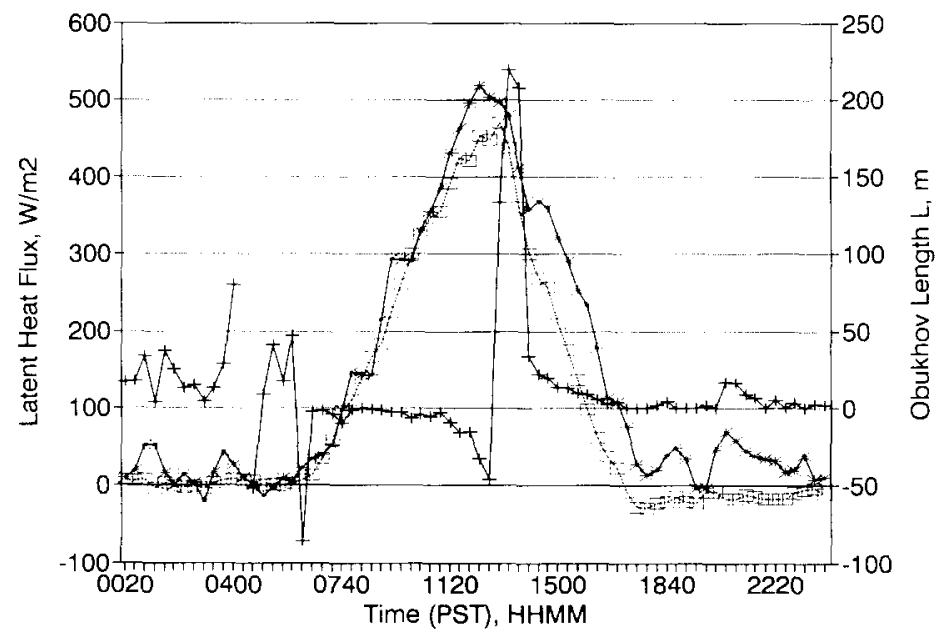

Fig. 12. Same as Fig. 11, for Julian day 271, 1990. 


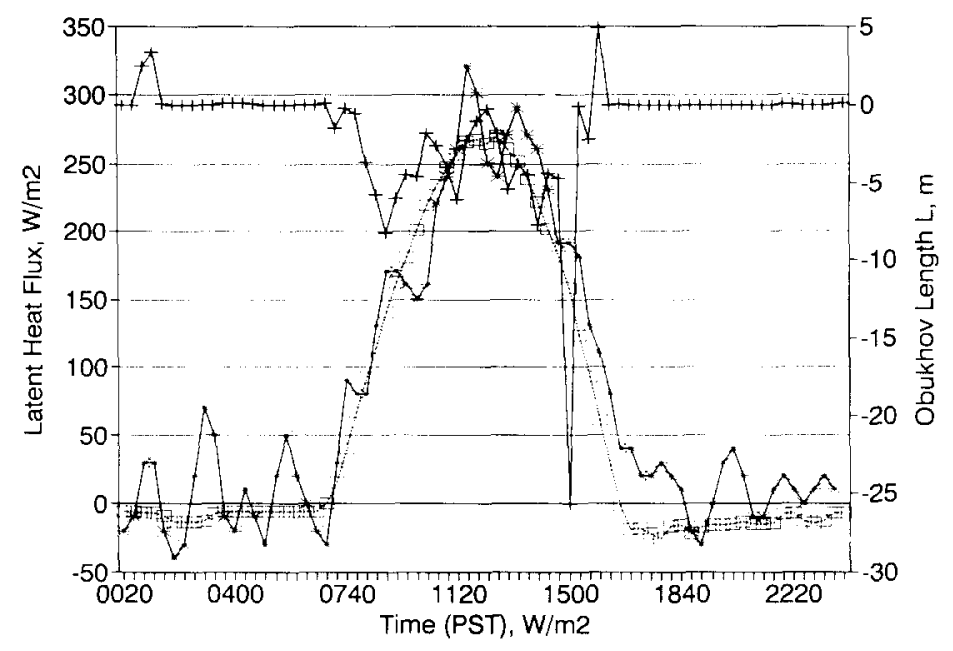

Fig. 13. Same as Fig. 11, for Julian day 297, 1990.

Once advection exceeds the minimal level, however, the predicted evaporation rate decreases symmetrically below the Priestley-Taylor estimates. The impact of advection over the wet surface is parameterized by accounting for the negative sensible heat flux as an adjustment to $E_{\mathrm{w}}$ when the potential evaporation (Penman-Brutsaert) is greater than $\left(R_{\mathrm{n}}-G\right)$. This demonstrates that the Bouchet hypothesis is suitable for short time periods over a wet surface.

\section{ACKNOWLEDGMENTS}

The authors thank M. Mata for his assistance in maintaining the field, and K. Tanji for his support. This work was supported in part by UC Salinity/ Drainage Task Force (90-14), UC Kearney Foundation of Soil Science, and the INCOR cooperative grant. The authors also thank the referees for their helpful comments.

\section{REFERENCES}

Abramopoulos, F., Rosenzweig, C. and Choudhury, B., 1988. Improved groundwater hydrology calculations for global climate models (GCM): Soil water movement and evapotranspiration. J. Climate., 1: 921-941.

Ali, M.F. and Mawdsley, J.A., 1987. Comparison of two recent models for estimating actual evapotranspiration using only recorded data. J. Hydrol., 93: 257-276.

Bouchet, R.J., 1963. Evapotranspiration réele et potentielle, signification climatique. Gen. Assem. Berkeley, Int. Assoc. Sci. Hydrol., 62: 134-142.

Brutsaert, W., 1975. A theory of local evaporation (or heat transfer) from rough or smooth surfaces at the ground level. Water Resour. Res., 11: 543-550. 
Brutsaert, W., 1982. Evaporation into the Atmosphere: Theory, History, and Applications. D. Reidel, Higham, MA, 229 pp.

Brutsaert, W., 1986. Catchment-scale evaporation and the atmospheric boundary layer. Water Resour. Res., 22(9): 39s-45s.

Brutsaert, W. and Stricker, H., 1979. An advection-aridity approach to estimate actual regional evapotranspiration. Water Resour. Res., 15: 443-450.

Businger, J., 1988. A note on the Businger-Dyer profiles. Boundary-Layer Meteorol., 42: $145-151$.

Cuenca, R.H., 1989. Irrigation System Design: An Engineering Approach. Prentice-Hall, Englewood Cliffs, NJ, 552 pp.

Davies, J.A. and Allen, C.D., 1973. Equilibrium, potential and actual evaporation from cropped surfaces in southern Ontario. J. Appl. Meteorol., 12: 649-657.

De Bruin, H.A.R. and Holtslag, A.A.M., 1982. A simple parameterization of the surface fluxes of sensible and latent heat during daytime compared with the Penman-Monteith concept. J. Appl. Metereol. Soc., 21: 1610-1621.

Dickinson, R.E., Henderson-Sellers, A., Kennedy, P.J. and Wilson, M.F., 1986. Biosphereatmosphere transfer scheme (BATS) for NCAR community climate model. NCAR Tech. Note, Atmos. Anal. Prediction Div. Nat. Center Atmos. Res., Boulder, CO.

Doorenbos, J. and Pruitt, W.O., 1977. Guidelines for predicting crop water requirements. FAO Irrigation and Drainage Paper, 24.

Doyle, P., 1990. Modelling catchment evaporation: An objective comparison of the Penman and Morton approaches. J. Hydrol., 121: 257-276.

Dyer, A.J., 1974. A review of flux profile relationships. Boundary-Layer Meteorol., 7: 363-372.

Eagleson, P.S., 1986. The emergence of global scale hydrology. Water Resour. Res., 22: 6s-14s.

Fortin, J.P. and Seguin, B., 1975. Estimation de L'ETR régionale à partir de l'ETP locale: utilization de la relation de Bouchet à différentes échelles de temps. Ann. Agron., 26: 537-554.

Granger, R.J. and Gray, D.M., 1990. Examination of Morton's CRAE model for estimating daily evaporation from field-sized areas. J. Hydrol., 120: 309-325.

Jury, W.A. and Tanner, C.B., 1975. Advection modifications of the Priestley and Taylor formula. Agron. J., 40: 840-842.

Katul, G.K. and Parlange, M.B., 1991. A Penman-Brutsaert model for wet surface evaporation. Water Resour. Res., in press.

Kustas, W.P., 1990. Estimates of evapotranspiration with a one- and two-layer model of heat transfer over partial canopy cover. J. Appl. Meteorol., 29: 704-715.

Le Meur, R. and Lu, Z., 1990. Evaluation of three evapotranspiration models in terms of their applicability to an arid region. J. Hydrol., 114: 395-411.

Mahrt, L. and Ek, M., 1984. The influence of atmospheric stability on potential evaporation. J. Climate Appl. Meteorol., 23: 222-234.

Mintz, Y., 1984. The sensitivity of numerically simulated climates to land surface boundary conditions. In: J.T. Houghton (Editor), The Global Climate. Cambridge University Press, Cambridge, pp. 79-103.

Monin, A.S. and Obukhov, A.M., 1954. Basic laws of turbulent mixing in the ground layer of the atmosphere. Tr. Geofiz. Inst. Akad. Nauk SSSR, 163-187.

Morton, F.I., 1969. Potential evaporation as a manifestation of regional evaporation. Water Resour. Res., 5: 1244-1255.

Morton, F.I., 1975. Estimating evaporation and transpiration from climatological observations. J. Appl. Meteorol., 14: 488-497. 
Morton, F.I., 1983. Operational estimates of areal evapotranspiration and their significance to the science and practice of hydrology. J. Hydrol., 66: 1-76.

Nash, J.E., 1989. Potential evaporation and "The complementary relationship". J. Hydrol., 111: $1-7$.

Nullet, D. and Giambelluca, T.W., 1990. Winter evaporation on a mountain slope, Hawaii, J. Hydrol., 112: 257-265.

Parlange, M.B. and Brutsaert, W., 1990. Are Radiosonde time scales appropriate to characterize boundary layer wind profiles? J. Appl. Meteorol., 29: 249-255.

Penman, H.L., 1948. Natural evaporation from open water, bare soil, and grass. Proc. R. Soc. Lond., Ser. A, 193: 120-146.

Priestley, C.H.B. and Taylor, R.J., 1972. On the assessment of surface heat flux and evaporation using large scale parameters. Mon. Weather Rev., 100: 81-92.

Pruitt, W.O. and Angus, A., 1960. Large weighing lysimeter for measuring evapotranspiration. Trans. ASAE, 3: 13-18.

Pruitt, W.O. and Lourence, F.J., 1985. Experiences in lysimetry for ET and surface drag measurements. Adv. Evapotranspiration, Am. Soc. Agric. Eng. Proc., pp. 51-69.

Rind, D., Goldberg, R., Hansen, J., Rosenzweig, C. and Ruedy, R., 1990. Potential evapotranspiration and the likelihood of future drought. J. Geophys. Res., 95: 9983-10004.

Rowntree, P.R. and Bolton, J.A., 1983. Simulation of the atmospheric response to soil moisture anomalies over Europe. Q. J. R. Meteorol. Soc., 109: 501-526.

Seguin, B., 1975. Influence de l'évapotranspiration régionale sur la mesure locale d'évapotranspiration potentielle. Agric. Meteorol., 15: 355-370.

Sellers, P.J. and Dorman, J.L., 1987. Testing the simple biosphere (SiB) using point micrometeorological and biophysical data. J. Climate Appl. Meteorol., 26: 622-651.

Shuttleworth, W.J., 1988. Macrohydrology - the new challenge for process hydrology. J. Hydrol., 100: 31-56.

Slatyer, R.O. and McIlroy, I.C., 1961. Practical Microclimatology. CSIRO, Melbourne, 310 pp.

Soares, J.V., Bernard, R., Taconet, O., Vidal-Midjar, D. and Weill, A., 1988. Estimation of bare soil evaporation from airborne measurements. J. Hydrol., 99: 281-296.

Stagnitti, F., Parlange, J.-Y. and Rose, C.W., 1989. Hydrology of a small wet catchment. Hydrol. Sci., 3: 137-150.

Stewart, R.B. and Rouse, W.R., 1976. A simple method for determining the evaporation of lakes and ponds. Water Resour. Res., 12: 623-628.

Stewart, R.B. and Rouse, W.R., 1977. Substantiation of the Priestley-Taylor parameter $\alpha=1.26$ for potential evaporation in high latitudes. J. Appl. Meteorol., 6: 649-650.

Stricker, H. and Brutsaert, W., 1978. Actual evapotranspiration over a summer period in the Hupsel Catchment. J. Hydrol., 39: 139-157.

Wallace, J.S., Gash, J.H.C. and Sivakumar, M.V.K., 1990. Research notes: preliminary measurements of net radiation and evaporation over bare soil and fallow bushland in the Sahel. Int. J. Climatol. 10: 203-210.

Warrilow, D.A. and Buckeley, E., 1989. The impact of land surface processes on the moisture budget of a climate model. Ann. Geophys., 7: 439-450.

Wyngaard, J.C., 1990. Scalar fluxes in the planetary boundary layer-theory, modeling, and measurement. Boundary-Layer Meteorol., 50: 49-77. 